\title{
Learning in innovation networks: some simulation experiments
}

\author{
Nigel Gilbert ${ }^{* a}$, Petra Ahrweiler ${ }^{\mathrm{b}}$ and Andreas $\mathrm{Pyka}^{\mathrm{c}}$ \\ ${ }^{a}$ Centre for Research in Social Simulation, \\ School of Human Sciences, University of Surrey, \\ Guildford GU2 7XH, \\ United Kingdom \\ ${ }^{b}$ Research Centre Media and Politics, \\ Institute for Political Science, \\ University of Hamburg, \\ Germany \\ ${ }^{c}$ Institute of Economics, \\ University of Augsburg, \\ Universitaetsstr. 16, \\ D-86135 Augsburg, \\ Germany
}

\begin{abstract}
According to the organizational learning literature, the greatest competitive advantage a firm has is its ability to learn. In this paper, a framework for modeling learning competence in firms is presented to improve the understanding of managing innovation. Firms with different knowledge stocks attempt to improve their economic performance by engaging in radical or incremental innovation activities and through partnerships and networking with other firms. In trying to vary and/or to stabilize their knowledge stocks by organizational learning, they attempt to adapt to environmental requirements while the market strongly selects on the results. The simulation experiments show the impact of different learning activities, underlining the importance of innovation and learning.
\end{abstract}

Keywords: Innovation, organizational learning, simulation

PACS: 89.65.Ef

${ }^{*}$ Corresponding author: Nigel Gilbert, School of Human Sciences, University of Surrey, Guildford GU2 7XH, United Kingdom. Tel: +44 1483 689173. Fax: +44 1483689551.

Email address: n.gilbert@surrey.ac.uk 
The SKIN model (Simulating Knowledge Dynamics in Innovation Networks; for a detailed introduction see [2]) is a multiagent simulation of firms that try to optimize their innovation performance in order to respond to the requirements of a constantly changing environment. Simulated scenarios can inform decision makers about the chances and risks of investing in different learning activities while taking into account the firm's markets, its clients, competitors and partners, its external and internal resources, and its strategic policies.

In this paper, we suggest that the SKIN model can be linked to the body of literature on "organizational learning" (OL) (for an early overview, see [14], and for later surveys, [3, 5, 21]). Following Garvin's statement [16] that only learning that can be measured will be useful to managers, the SKIN simulation shows the outcome of different learning activities. The model embodies some theoretical ideas from the OL literature and implements many OL concepts (e.g. from [4, 22, 23, 28]). Thus, the SKIN model is not only interesting for managers and other practitioners responsible for empirical learning processes within firms but also for scientists testing theories from the body of research on organizational learning.

\section{The Model}

SKIN is a multi-agent model containing heterogeneous agents that act and interact in a complex and changing environment. The agents represent innovative firms who try to sell their innovations to other agents and end users but who also have to buy raw materials or more sophisticated inputs from other agents (or material suppliers) in order to produce their outputs. This basic model of a market is extended with a representation of the knowledge dynamics in and between the firms. Each firm tries to improve its innovation performance and its sales by improving its knowledge base through adaptation to user needs, incremental or radical learning, and co-operation and networking with other agents. The elements and processes of the model will now be described in more detail, with an emphasis on the learning activities.

The core concept of the framework is the knowledge, which will manifest itself in the innovative production or delivery of manufactured and service products. The approach to knowledge representation used in the model is similar to Toulmin's evolutionary model of knowledge production [29]. This identified concepts, beliefs and interpretations as the 
"genes" of scientific/technological development evolving over time in processes of selection, variation and retention. Ackermann interpreted the works of Kuhn and Popper according to this perspective allowing for different selection systems [1]. More recent studies [10] discuss the idea of cultural replicators. A replicator is a unit which is copied - with random error and which can in a way decide on the probability of its own replication. Although Dawkins does not compare his "meme" as a cultural replicator with the gene as biological replicator, the implication seems obvious $[6,12]$. However, "memes" are usually located in mental states. This cognitive aspect would seem to confine the concept to individuals or require that collectivities have a mental state. Instead, the SKIN model uses a similar concept, a "kene", to represent the aggregate knowledge of an organization [17].

\subsection{The agents}

The individual knowledge base of a SKIN agent, its kene, contains a number of "units of knowledge". Each unit is represented as a triple consisting of a firm's capability $C$ in a scientific, technological or business domain (e.g. biochemistry), represented by an integer, its ability $A$ to perform a certain application in this field (e.g. a synthesis procedure or filtering technique in the field of biochemistry), represented by a real number, and the expertise level $E$ the firm has achieved with respect to this ability (represented by an integer). The firm's kene is its collection of $\mathrm{C} / \mathrm{A} / \mathrm{E}$-triples.

When it is set up, each firm has also a stock of initial capital. It needs this capital to produce for the market and to improve its knowledge base, and it can increase its capital by selling products. The amount of capital owned by a firm is a measure of its size and also influences the amount of knowledge that it can support, represented by the number of triples in its kene. Most firms are initially given an amount of starting capital taken from a uniform distribution between zero and an initial maximum capital allocation, but in order to model differences in firm size, a few randomly chosen firms can be given extra capital.

\subsection{The market}

Firms apply their knowledge to create innovative products that have a chance of being successful in the market. The special focus of a firm, its potential innovation, is called an 
innovation hypothesis. In the model, the innovation hypothesis (IH) is derived from a subset of the firm's kene triples.

The underlying idea for an innovation, modeled by the innovation hypothesis, is the source an agent uses for its attempts to make profits on the market. Developing the innovation hypothesis into a product is a mapping procedure where the capabilities and abilities of the innovation hypothesis are used to compute an index number that represents the product.

A firm's product, $P$, is generated from its innovation hypothesis as

$P=\left(C_{1} * A_{1}\right)+\left(C_{3} * A_{3}\right)+\left(C_{4} * A_{4}\right)+\ldots$ modulus $N$

where $N$ is a constant.

The product has a certain quality, which is also computed from the innovation hypothesis in a similar way, by multiplying the abilities and the expertise levels for each triple in the innovation hypothesis and normalizing the result. In order to realize the product, the agent needs some materials. These can either come from outside the sector ("raw materials") or from other firms, which generated them as their products. What exactly an agent needs is also determined by the underlying innovation hypothesis: the kind of material required for an input is obtained by selecting subsets from the innovation hypotheses and applying the standard mapping function (see equation 1 above).

These inputs are chosen so that each is different and differs from the firm's own product. In order to be able to engage in production, all the inputs need to be obtainable on the market, i.e. provided by other agents or available as raw materials. If the inputs are not available, the agent is not able to produce and has to give up this attempt to innovate. If there is more than one supplier for a certain input, the agent will choose the one at the cheapest price and, if there are several similar offers, the one with the highest quality.

If the agent can go into production, it has to find a price for its own product that takes account of the input prices it is paying and a possible profit margin. While the simulation starts with product prices set at random, as the simulation proceeds, a price adjustment mechanism increases the selling price if there is much demand, and reduces it (but no further than the 
total cost of production) if there are no customers. A range of products are considered to be 'end-user' products and are sold to customers outside the sector: there is always a demand for such end-user products provided that they are offered at or below a fixed end-user price. An agent will then buy the requested inputs from its suppliers using its capital to do so, produces its output and puts it on the market for others to purchase. Using the price adjustment mechanism, agents are able to adapt their prices to demand and in doing so learn by feedback.

In making a product, an agent applies the knowledge in its innovation hypothesis and this increases its expertise in this area. This is the way that learning by doing/using is modeled. The expertise levels of the triples in the innovation hypothesis are increased by 1 and the expertise levels of the other triples are decremented by 1. Unused triples in the kene eventually drop to an expertise level of 0 and are deleted from the kene; the corresponding abilities are "forgotten" or "dismissed" [19].

\subsection{Learning and co-operation: improving innovation performance}

In trying to be successful on the market, the firms are dependent on their innovation hypothesis and thus on their kene. If a product does not meet any demand, the firm has to adapt its knowledge in order to produce something else for which there are customers [15]. In the model, a firm has several ways of improving its performance, either alone or in cooperation, and in either an incremental or a more radical fashion. All strategies have in common that they are costly: the firm has to pay a "tax" as the cost of applying an improvement strategy.

\subsubsection{Incremental research}

If a firm's previous innovation has been successful, i.e. it has found buyers, the firm will continue selling the same product in the next round. However, if there were no sales, it considers that it is time for change (evaluating feedback). If the firm still has enough capital, it will carry out "incremental" research (R\&D in the firm's labs).

Performing incremental research [9] means that a firm tries to improve its product by altering one of the abilities chosen from the triples in its innovation hypothesis, while sticking to its focal capabilities. The ability in each triple is considered to be a point in the respective 
capability's action space. To move in the action space means to go up or down by an increment, thus allowing for two possible "research directions".

Initially, the research direction of a firm is set at random. Later it learns to adjust to success or failure: if a move in the action space has been successful the firm will continue with the same research direction within the same triple; if it has been a failure, the firm will randomly select a different triple from the innovation hypothesis and try again with a random research direction.

\subsubsection{Radical research}

A firm under serious pressure that is in danger of becoming bankrupt will turn to more radical measures, by exploring a completely different area of market opportunities. In the model, an agent under financial pressure turns to a new innovation hypothesis after first "inventing" a new capability for its kene. This is done by randomly replacing a capability in the kene with a new one and then generating a new innovation hypothesis.

\subsubsection{Partnerships}

An agent in the model may consider partnerships (alliances, joint ventures etc.) in order to exploit external knowledge sources. The decision whether and with whom to co-operate is based on mutual observations of the firms, which estimate the chances and requirements coming from competitors, possible and past partners, and clients.

The information a firm can gather about other agents is provided by a marketing feature: to advertise its product, a firm publishes the capabilities used in its innovation hypothesis. (Capabilities not included in its innovation hypothesis and thus in its product, are not visible externally and cannot be used to select the firm as a partner.) The firm's advertisement is then the basis for decisions by other firms to form or reject co-operative arrangements.

In experimenting with the model, we can choose between two different partner search strategies, both of which compare the firm's own capabilities as used in its innovation hypothesis and the possible partner's capabilities as seen in its advertisement. Applying the conservative strategy, a firm will be attracted by a possible partner that has similar 
capabilities; using a progressive strategy the attraction is based on the difference between the capability sets.

Previously good experience with former contacts generally augurs well for renewing a partnership. This is mirrored in the model: to find a partner, the firm will look at previous partners first, then at its suppliers, customers and finally at all others. If there is a firm sufficiently attractive according to the chosen search strategy (i.e. with attractiveness above the 'attractiveness threshold'), it will stop its search and offer a partnership. If the possible partner wishes to return the partnership offer, the partnership is set up.

The model assumes that partners learn only about the knowledge being actively used by the other agent. Thus, to learn from a partner, a firm will add the triples of the partner's innovation hypothesis to its own. For capabilities that are new to it, the expertise levels of the triples taken from the partner are reduced by 1 in order to mirror the difficulty of integrating external knowledge [8]. For partner's capabilities that are already known to it, if the partner has a higher expertise level, the firm will drop its own triple in favor of the partner's one; if the expertise level of a similar triple is lower, the firm will stick to its own version. Once the knowledge transfer has been completed, each firm continues to produce its own product, possibly with greater expertise as a result of acquiring skills from its partner.

\subsubsection{Networks}

If the firm's last innovation was successful, i.e. the amount of its profit in the previous round was above a threshold, and the firm has some partners at hand, it can initiate the formation of a network. This can increase its profits because the network will try to create innovations as an autonomous agent in addition to those created by its members and will distribute any rewards to its members who, in the meantime, can continue with their own attempts, thus providing a double chance for profits. However, the formation of networks is costly, which has two consequences: only firms with enough capital can form or join a network and no firm can be member of two networks at the same time.

Networks are "normal" agents, i.e. they get the same amount of initial capital as other firms and can engage in all the activities available to other firms. The kene of a network is the union of the triples from the innovation hypotheses of all its participants. If a network is successful 
it will distribute any earnings above the amount of the initial capital to its members; if it fails and becomes bankrupt, it will be dissolved.

\subsection{Start-ups}

If a sector is successful, new firms will be attracted into it. This is modeled by adding a new firm to the population when any existing firm makes a substantial profit. The new firm is a clone of the successful firm, but with its kene triples restricted to those in the successful firm's advertisement, and an expertise level of 1 . This models a new firm copying the characteristics of those seen to be successful in the market. As with all firms, the kene may also be restricted because the initial capital of a start-up is limited and may not be sufficient to support the copying of the whole of the successful firm's innovation hypothesis.

\section{$3 \quad$ Organizational Learning}

In 1938, the American philosopher John Dewey introduced the concept of experiential learning as a permanent activity cycle [13], starting a discussion among educationalists about feedback learning and learning by doing. This discussion, however, referred mostly to individuals. It was in 1973 that Donald Michael introduced the idea of organizational learning (OL) [24]. Since then, the field of OL has grown steadily. In the 1970s, Argyris and Schön's influential monograph [4] proposed that a learning organisation is one that is permanently changing its interpretation of the environment. In doing so, the organization learns new things and forgets old ones. Drawing on their background as action theorists, Argyris and Schön show how these interpretations are gained and how they are connected to different organizational behaviors.

We can apply the SKIN model to many of the ideas of the Argyris/Schön framework and use it to examine the assumption that, in the words of de Geus [11], the greatest competitive advantage for any firm is its ability to learn. As we have seen in the previous section, in the SKIN model, firms can:

1. use their capabilities (learning by doing/using);

2. learn to estimate their success via feedback from markets and clients (learning by feedback) 
3. improve their own knowledge incrementally when the feedback is not satisfactory in order to adapt to rising technological and/or economic standards (adaptation learning, incremental learning)

4. radically change their capabilities in order to meet completely different requirements of markets and clients (innovative learning, radical learning)

Firms may also be also active on the meta level (called in the OL literature, the double-loop learning level) of the model. They can:

1. forget their capabilities (clean up their knowledge space)

2. decide on their individual learning strategies themselves (e.g. incremental or radical learning), constructing and changing the strategies according to their past experience and current context. The context consists of external factors such as the actions of clients, competitors and partners, and the availability of technical options, and internal factors such as their capital stock and the competencies available to them.

3. engage in networking and partnerships to absorb and exploit external knowledge sources, to imitate and emulate, and to use synergy effects (participative learning).

Furthermore, the SKIN simulation models some insights from empirical learning research, for example, addressing the difficulty of including external knowledge into the firm (e.g.[7]), the ongoing diffusion of innovation-relevant knowledge in the market, and the influence of firms entering the market.

Models and simulation tools have long been used for strategic planning (cf. [20, 25, 26, 27] etc.). In addition, a lot of work has been done lately in the area of intelligent management and decision support systems (for a recent review see [18]). In contrast to these, the SKIN approach allows strategic computational agents to act experimentally in complex knowledgebased scenarios. It is possible to track single firms in the simulation in order to observe their strategic learning behaviors in different situations and their outcomes, or to consider the effect of different forms of learning on a sector as a whole, the approach taken in this paper.

\section{Some Experiments}

The SKIN simulation may be used to test the impact of various learning activities on the survival and effectiveness of firms in a highly competitive and dynamic market. In the section, we present some simulations examining the effects of organizational learning on the 
performance of the model. In trying to vary and/or to stabilize their knowledge stocks by organizational learning, the simulated firms attempt to adapt to environmental requirements while the simulated market rewards those that are most successful.

We begin with some baseline experiments, in which no firm is able to learn. All firms start with a randomly generated kene and have no possibility of changing it through learning. Moreover, the prices of products are fixed and cannot be changed to suit the market. Not surprisingly, in this scenario, there is very little trading activity, because few firms are able to find suppliers for their needed inputs, and those that can are likely to find their requirements too expensive to be affordable. The market as a whole fails to 'take off', almost all firms fail to trade, and the consequence is that firms do not make a profit. Nevertheless all firms have to pay a tax just to remain in the market, which is taken from their starting capital. When it has used up all its capital, a firm 'dies' and is removed from the simulation. Eventually, the simulation ends with no remaining firms.

The pattern for scenarios when firms are only capable of learning by using and learning by feedback is similar. These types of learning operate at the market level, but do not affect the innovation performance of the firms. While adjustment of prices can help when a firm is making a product that is in demand, but which is too expensive for the customers, it is of no avail if the product is the wrong one - there is no demand for it - or the product cannot be made because the requisite inputs are not available. This is usually the situation in these basic scenarios, where the selection of products available is determined by the random chance of the initial kene configurations, and where there is no opportunity to engage in innovation to produce new, more desirable products. As Figure 2 shows, the population of firms decreases steadily until no more remain.

The picture changes once we allow adaptive learning by means of simulated research. Now the firms are able to modify their knowledge bases, generate new products and adapt the inputs that they require to make these products. For many firms, the learning that they are able to do will be unsuccessful and their fate will be the same as in the baseline scenario: little or no profit, a regular tax, although one larger than before to pay for the research they are doing, and eventual bankruptcy and removal from the simulation. Some firms, however, will strike lucky and find a product for which there are reasonably priced inputs available and a customer able to purchase. Profits accrue to these firms, which become steadily richer while their products remain in demand. However, the environment for these firms consists of 
all the other firms and their products. This is a highly dynamic environment and it is likely that before too long, either a firm from which it is buying an input or a firm to which it is selling its product will change its kene (and thus its inputs and product) or go out of business altogether. This will initiate a cascade of changes that may leave it without a viable product. However, it can live off its accrued capital while it searches for an alternative.

Thus, in a scenario in which adaptation of firms' kenes is possible, we obtain an initial sharp reduction in the number of firms as those that are not viable drop out, followed by recovery as firms accumulate capital from successful trading, and because of their success, attract newcomers into the market. A detailed look at the first 100 time periods (Figure 1), reveals that initially, overall, very few firms are capable of making products because the inputs they need are not available on the market. During the early steps, the firms 'redesign' their products to accommodate the inputs on the market and can then offer the products for sale. Then they redesign their products to match the requirements of their customers and many firms succeed in making sales. Those that either fail to adjust their innovation hypotheses so that they only require inputs that can be bought, or which make products that no other firm wants to buy, run out of capital and 'die'. The number of firms stabilizes at between 500 and 600 (measured in repeated runs under the same conditions). This can be seen in Figure 2, which plots the number of firms by time, in an experiment where all firms are capable of learning through incremental research, in addition to learning by doing and by feedback.

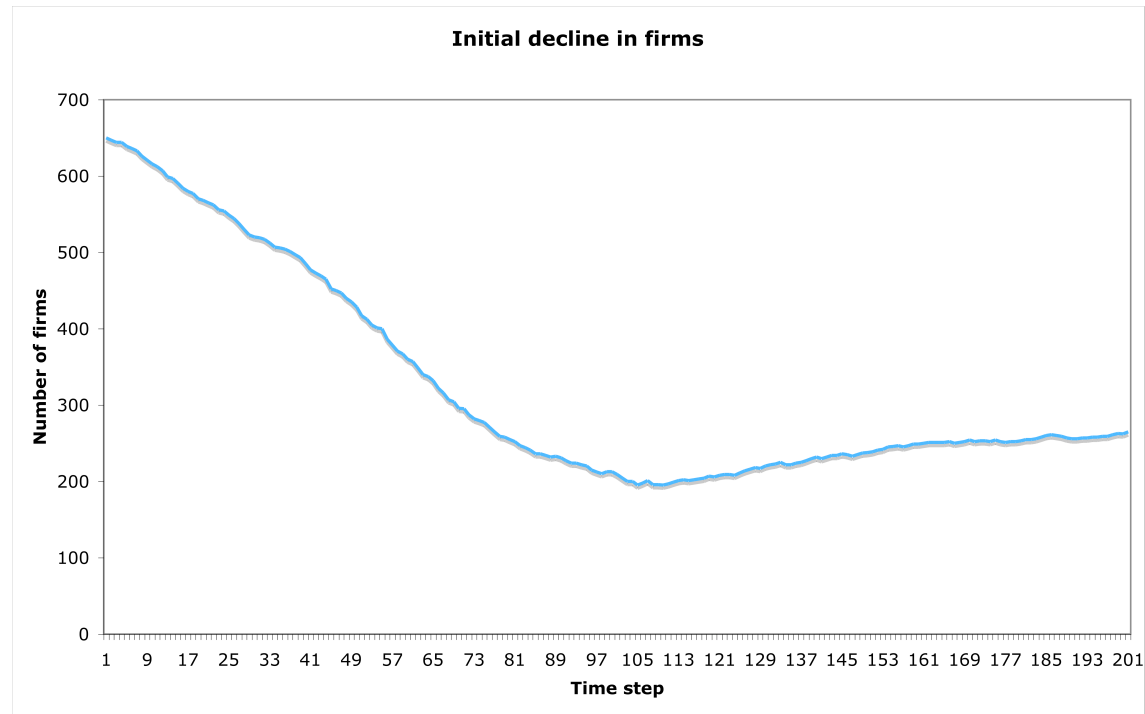

Figure 1 The first 150 time steps, showing the initial shake out of firms when the simulated sector can perform incremental research and price adjustment 


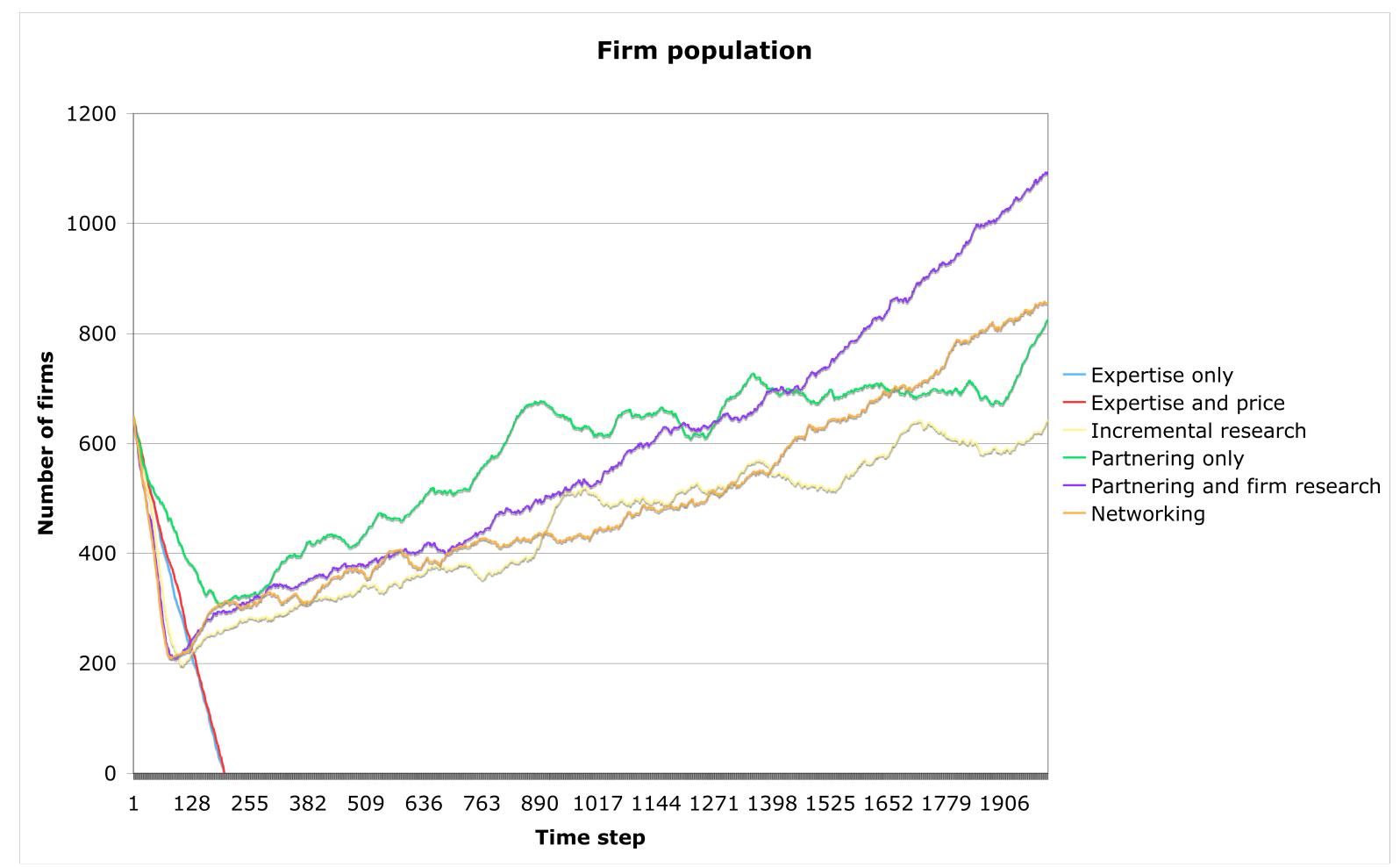

Figure 2 The population of firms over the first 2000 time steps, for various combinations of organizational learning

While incremental research does allow a firm to improve its product through varying its abilities, it is stuck with its initial, randomly assigned, basket of capabilities. Radical research (innovative learning) allows the firm to branch out, absorbing or creating new capabilities that can lead to completely new products. We allow the firms to engage in such radical research strategies only when they are close to running out of funds, and thus close to 'death'. If their remaining capital falls below a threshold value, they acquire a new capability in exchange for an existing one, then generate a new innovation hypothesis and, if they can find the required inputs and a customer, a new product. Such radical research is very risky and in the model, only succeeds about 5 per cent of the time (i.e. the innovation hypothesis generated from a radical research effort only makes a surplus in about 1 in 20 cases). Nevertheless, the possibility of doing radical research has an effect on the overall success of the firms. The median number of steps before firms lose all their capital rises from about 40 to about 60 because of the opportunity for a 'fresh start' that undertaking a radical research programme offers to those that manage to discover a successful innovation hypothesis. 


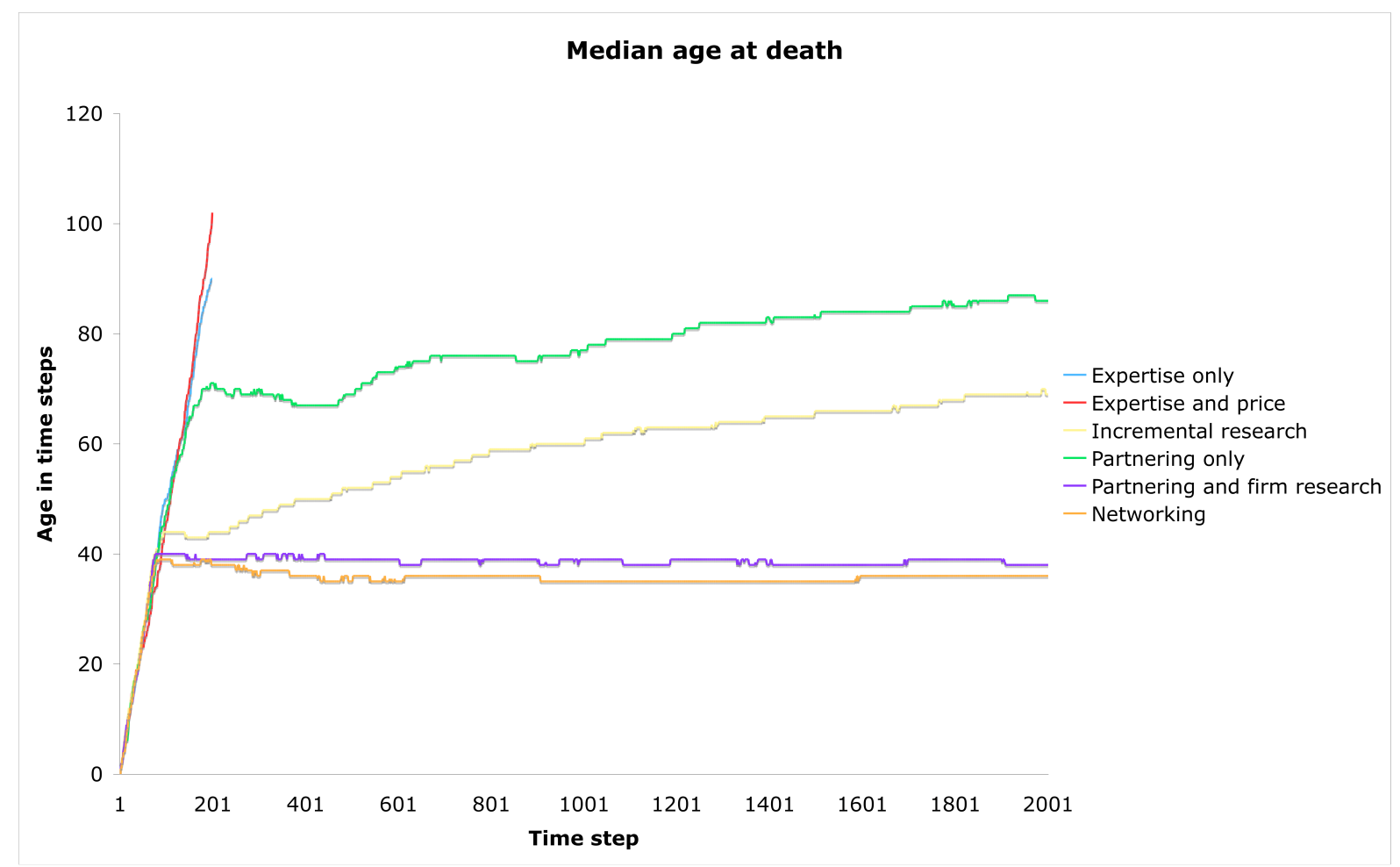

Figure 3 Median age of firms at the time step when they lose all their capital, by type of organizational learning

A way of acquiring new knowledge in addition to incremental or radical research is to obtain it from other firms though some form of collaboration. Such participatory learning is modeled by the formation of partnerships between similar firms. Partners exchange capabilities, thus introducing new ideas into the firm from outside, rather than through internal research. Figure 2 also shows the changes in the population of firms when all the firms are able to engage in partnerships, but do no incremental or radical research. It will be seen that the innovations that are introduced through partnership are slightly more successful (as judged by the growth in the population of firms) than those that are obtained by internal research, perhaps because partnering allows the introduction of new capabilities from partners, while incremental research only improves the abilities for capabilities that the firm already possesses. The firms employ the 'conservative' strategy in these experiments, which means that they partner with other firms that have similar innovation hypotheses, thus limiting the amount of novelty. Moreover, firms preferentially partner with others that they have previously collaborated with, again limiting the possibility of novelty. Nevertheless, sufficient innovation is introduced that the sector as a whole is able to create a sustainable market and grow slightly faster than if each form operated with only its own innovation resources. 
Allowing firms to engage in partnership formation together with incremental and radical research provides the best resources for innovation and yields the fastest growth in the number of firms. With this combination of types of learning, not only are firms able to acquire capabilities from partners, they are also able to improve the abilities using their own internal research activities.

Partnerships are dissolved at the end of each time step and only affect the knowledge base of the partners. However, experienced partners are also able to create networks that can make products on their own account, contributing any profit to the network members. Figure 6 also shows the population growth when all firms are allowed to become network members if they wish. The curve is shows slower growth than partnering plus internal firm research because the network activities have the effect of generating additional competition for the firms. Figure 4 shows the typical near power law distribution of size of the networks, also found in real innovation networks.

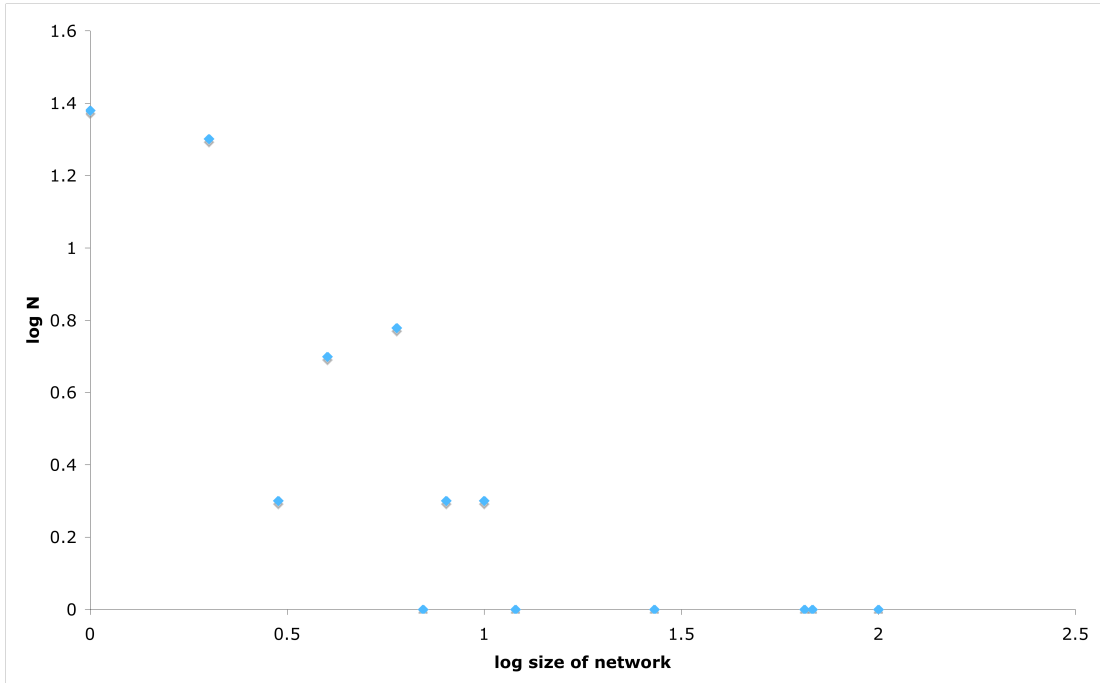

Figure 4 Log-log plot of network size (number of firms per network) after 2000 time steps.

\section{Conclusions}

In this paper, a framework for modeling learning competence in firms is presented to improve the understanding of managing innovation. Focusing on their learning competencies, firms with different knowledge stocks attempt to improve their economic performance by choosing or suppressing radical or incremental innovation activities and by engaging in partnerships and networks with other firms. In trying to vary and/or to stabilize their knowledge stocks by organizational learning, they attempt to adapt to environmental requirements while the market 
strongly selects on the results. The simulation experiments show the impact of different learning activities, underlining the importance of innovation and learning. It demonstrates the importance of finding new capabilities from outside the firm, either through partnering or radical research. It also shows that the simpler forms of organizational learning, such as learning by doing and learning by feedback, are of limited value by themselves in the highly dynamic environment of modern knowledge based market sectors, although they are of significance when combined with other forms of learning.

The model also demonstrates the possibilities opened up by simulation for carrying out experiments on a model that would be impossible to perform in the real world. Clearly, it would not be practicable to constrain actual firms in their learning capacities in order to study the effect on their success and determine the causal consequences, still less to do this for a whole market sector. But as this paper has shown, it is possible and revealing to do so on a model of a sector. This paper has only made a start in examining the complex relationships between firm and sector success and organizational learning; there are many more possibilities that await investigation.

\section{Appendix}

The code for the NetLogo model on which this paper is based is available on request from the first author.

The simulation runs described in this paper use the following parameter settings:

- Initial capital of firms: taken from a uniform random distribution between 0 and 20,000

- Initial population of firms: 650

- Number of large firms, with extra capital at the start: 0

- Range of product index numbers in the sector: 0.0 to 100.0

- Maximum difference between product and input index numbers for them to be considered substitutable: 1.0

- All products with a product number below 5.0 are considered to be 'raw-materials' and all those with numbers above 95 are 'end-user' products.

- Price of raw materials: 1

- Maximum price of end-user products: 1000

- Profit required to attract new start-ups: 400 
- Partnering search strategy: conservative

- Attractiveness threshold to allow two firms to partner: 0.3

- Capital cut-off below which firms do radical rather than incremental research: 1000

- Taxes: per time step: 200; per incremental research attempt: 100; per radical research attempt: 100: per partner: 100

\section{References}

[1] R. Ackermann, The Philosophy of Science, Pegasus, New York, 1970.

[2] P. Ahrweiler, A. Pyka and N. Gilbert, Simulating knowledge dynamics in innovation networks, in R. Leombruni and M. Richiardi, eds., Industry and Labor Dynamics: The agent-based computational economics approach, World Scientific, Singapore, 2004, pp. 284-296.

[3] B. Amable, The diversity of modern capitalism, Oxford University Press, Oxford, 2003.

[4] C. Argyris and D. A. Schön, Organizational Learning: a theory of action perspective, Addison-Wesley, Reading, MA, 1996.

[5] T. Bahlmann, The learning organization in a turbulent environment, Human Systems Management, 9 (1990), pp. 249-256.

[6] S. Blackmore, The meme machine, Oxford University Press, Oxford, 1999.

[7] U. Cantner and A. Pyka, Absorbing technological spillovers: simulations in an evolutionary framework, Industrial and Corporate Change, 7 (1998), pp. 369-397.

[8] W. M. Cohen and D. Levinthal, Absorptive capacity: a new perspective on learning and innovation, Administrative Science Quarterly, 35 (1990), pp. 128-152.

[9] W. M. Cohen and D. Levinthal, Innovation and Learning: the two faces of R\&D, The Economic Journal, 99 (1989), pp. 569-596.

[10] R. Dawkins, The Selfish Gene, Oxford University Press, Oxford, 1989.

[11] A. de Geus, The Living Company, Brealy, London, 1997.

[12] D. C. Dennett, Darwin's Dangerous Idea: evolution and the meanings of life, Penguin, London, 1995.

[13] J. Dewey, Experience and Education, Collier, new York, 1938.

[14] M. Dodgson, Organizational learning: a review of some literatures, Organization Studies, 14 (1993), pp. 375-394.

[15] R. B. Duncan, Modifications in decision structure in adapting to the environment: some implications for organizational learning, Decision Sciences, 5 (1974), pp. 705-725.

[16] D. A. Garvin, Building a learning organization, Harvard Business Review (1993), pp. 81-91.

[17] G. N. Gilbert, A simulation of the structure of academic science, Sociological Research Online, 2 (1997), pp. http://www.socresonline.org.uk/socresonline/2/2/3.html.

[18] J. Gupta, G. Forgionne and M. Mora, Intelligent decision-making support systems: foundations, applications, and challenges, Springer, Berlin, 2006.

[19] B. Hedberg, How organizations learn and unlearn, in P. C. Nystrom and W. H. Starbuck, eds., Handbook of Organizational Design, Oxford University Press, Oxford, 1981.

[20] W. C. House, ed., Decision Support Systems: a data-based, model-oriented, user-developed discipline, Petrocelli, New York, 1983.

[21] A. Lam, Organizational learning in multinationals: R\&D networks of Japanese and US MNEs in the UK, Journal of Management Studies, 40 (2003), pp. 673-703.

[22] D. A. Levinthal and J. G. March, The myopia of learning, Strategic Management Journal, 14 (1993), pp. 95-112.

[23] J. G. March and J. P. Olsen, The uncertainty of the past: organizational learning under ambiguity, European Journal of Political Research, 3 (1975), pp. 147-171.

[24] D. M. Michael, On learning to plan and planning to learn, Jossey-Bass, Hoboken, NJ, 1973.

[25] P. Milling, Modeling Innovation processes for decision support and management simulation, System Dynamics Review, 12 (1996), pp. 211-234.

[26] G. E. Monahan, Management Decision Making: Spreadsheet modeling, analysis and application, Cambridge University Press, Cambridge, 2000.

[27] A.-W. Scheer, Business Process Engineering: reference models for industrial enterprises, Springer, Berlin, 1994.

[28] P. M. Senge, The leader's new work: building learning organizations, Sloan Management Review (1990), pp. 7-23.

[29] S. Toulmin, The Philosophy of Science: an introduction, Hutchinson, London, 1967. 
